\title{
Alterações no Código Florestal Brasileiro: impactos potenciais sobre a ictiofauna
}

\author{
Lilian Casatti ${ }^{1,2}$ \\ ${ }^{1}$ Departamento de Zoologia e Botânica, Instituto de Biociências, Letras e Ciências Exatas - IBILCE, \\ Universidade Estadual Paulista - UNESP, Rua Cristóvão Colombo, $n$. 2265, \\ CEP 15054-000, São José do Rio Preto, SP, Brasil \\ ${ }^{2}$ Autor para correspondência: Lilian Casatti,e-mail:licasatti@gmail.com
}

CASATTI, L. Changes in the Brazilian Forest Code: potential impacts on the ichthyofauna. Biota Neotrop. 10(4): http://www.biotaneotropica.org.br/v10n4/en/abstract?article+bn00310042010.

\begin{abstract}
In this paper is presented an analysis of possible impacts that the reduction of native vegetation, especially riparian forests, can have on the fish fauna. Three sets of primary functional aspects performed by riparian forests are discussed: transferring of solar energy to the aquatic environment, trapping nutrients and sediments that enter the rivers and transfer of organic material between the terrestrial and aquatic environments. Any modification which results in further loss of native vegetation, in permanent preservation areas or in protection reserves, may generate losses of species, faunal homogenization and reduction of fish biomass.
\end{abstract}

Keywords: conservation, stream, fishes, habitat loss.

CASATTI, L. Alterações no Código Florestal Brasileiro: impactos potenciais sobre a ictiofauna. Biota Neotrop. 10(4): http://www.biotaneotropica.org.br/v10n4/pt/abstract?article+bn00310042010.

Resumo: É apresentada uma análise dos possíveis impactos que a diminuição da vegetação nativa, notadamente das florestas ripárias, pode causar sobre a ictiofauna. Três conjuntos de aspectos funcionais primordiais desempenhados pelas florestas ripárias são discutidos: transferência de energia solar ao ambiente aquático, interceptação de nutrientes e sedimentos que adentram nos rios e trocas de material orgânico entre o sistema terrestre e aquático. Conclui-se que qualquer alteração que se traduza em mais perdas de vegetação nativa, seja em áreas de preservação permanente ou em reservas legais, pode gerar perdas de espécies, homogeneização faunística e diminuição de biomassa íctica.

Palavras-chave: conservação, riachos, peixes, perda de hábitat.

\section{Introdução}

As áreas florestais apresentam importantes funções para a integridade de sistemas aquáticos e para os peixes, sendo particularmente importante na medida em que essa relação de interface terra-água se intensifica, ou seja, em riachos e nascentes (Barrela et al. 2001). Há uma extensa literatura de revisão sobre o tema, em que se destaca o papel e a necessidade de proteção das áreas florestais, em especial das florestas ripárias (Gregory et al. 1991, Naiman \& Décamps 1997, Chapman, L.J. \& Chapman, C.A. 2002, Pusey \& Arthington 2003). Antes de abordar o papel da floresta para os peixes, é importante citar que há 2.587 espécies de peixes de água doce no Brasil (Buckup et al. 2007), o que representa 37\% dos vertebrados conhecidos em nosso país (Lewinsohn \& Prado 2005). Com exceção de 200 espécies que parecem estar mais associadas a rios de grande porte (Buckup 1999, Buckup et al. 2007), a maioria mostra alta fidelidade a riachos e, portanto, íntima relação com florestas ripárias. Estes organismos atuam como predadores que regulam populações de insetos aquáticos e algas, participam do processamento da matéria orgânica e também são presas para peixes maiores, muitos destes usados pelo homem como alimento. Em quais pontos a proposta substitutiva ao Projeto de Lei no 1.876/1999 se mostra mais frágil por influenciar os processos biológicos vitais para a ictiofauna? Antes de abordar o cerne da discussão em pauta, é necessário detalhar os principais aspectos funcionais das florestas ripárias para a ictiofauna.

\section{Aspectos funcionais das florestas ripárias para a ictiofauna}

As relações funcionais entre as florestas ripárias e a ictiofauna podem ser agrupadas em três conjuntos principais: i) transferência de energia solar ao ambiente aquático, ii) interceptação de nutrientes e sedimentos que adentram nos rios e iii) trocas de material orgânico entre o sistema terrestre e aquático (Pusey \& Arthington 2003). Peixes são ectotérmicos, ou seja, incapazes de regular sua temperatura e, portanto, dependem da temperatura externa para ajustar a sua própria; como a retirada da floresta ripária expõe o meio aquático a temperaturas mais elevadas, o controle metabólico dos organismos ectotérmicos pode ser afetado (Pusey \& Arthington 2003). Com mais luz, há aumento de produção de cianobactérias (muitas tóxicas), algas e plantas aquáticas que, em excesso, promovem eutrofização (Tundisi, J.G \& Tundisi, T.M. 2008: 526), ocasionando mortandades de peixes. Com o aumento da temperatura, a quantidade de gases dissolvidos (p. ex., oxigênio), a tolerância dos peixes a determinadas substâncias tóxicas diminuem (p. ex., amônia, Linton et al. 1997) e a reprodução dos peixes é afetada, pois a temperatura regula desde a fase de maturação gonadal até o desenvolvimento das larvas (Llewellyn 1973, Lowe Mc-Connell 1999). A orientação visual na busca por alimentos e reconhecimento de parceiros tem papel fundamental na vida de muitas espécies de peixes e isso depende da quantidade e do tipo de luz que atravessa o dossel da floresta (Pusey \& Arthington 2003); ainda, para ocultarem-se de predadores, os peixes exploram 
manchas de luz no hábitat, proporcionadas pelo sombreamento e, neste sentido, a supressão das florestas ripárias homogeneíza a luz, prejudicando o desempenho dos peixes (Pusey \& Arthington 2003). A radiação UV também pode ser letal a larvas de diversas espécies de peixes tropicais (Pusey et al. 2001).

As florestas ripárias interceptam sedimentos, fertilizantes e pesticidas que adentram nos rios através escoamento superficial ou subterrâneo (Naiman et al. 2005). Diversos estudos confirmam esse papel mitigador (p. ex., Townsend \& Douglas 2000, Lorion \& Kennedy 2009) e demonstram influências negativas do aumento de sedimentação sobre alimentação (Berkman \& Rabeni 1987, Rabeni \& Smale 1995), capacidade de forrageio (Berkman \& Rabeni 1987) e desenvolvimento das larvas de peixes (Morgan et al. 1983).

As florestas também influenciam as trocas de material orgânico entre o sistema terrestre e aquático (Pusey \& Arthington 2003); este material orgânico (folhas, troncos, frutos) serve como substrato para o desenvolvimento de microrganismos utilizados como alimento por invertebrados e peixes (Angermeier \& Karr 1984, Pusey \& Arthington 2003), promove abrigo aos peixes (Angermeier \& Karr 1984), funciona como marcações que ajudam a navegação dos peixes (Crook \& Robertson 1999) e também influencia o perfil hidráulico de cursos d'água. Há várias evidências científicas de que a diminuição do aporte destes elementos pode causar a diminuição da quantidade de espécies, densidade e biomassa dos peixes (Angermeier \& Karr 1984, Neumann \& Wildman 2002, Lester et al. 2007, Schneider \& Winemiller 2008). Da mesma maneira que o sistema terrestre exporta elementos orgânicos para o riacho, este os exporta para o sistema terrestre, principalmente através da eclosão de insetos que passam a fase juvenil na água (Marczak \& Richardson 2007). Estes insetos são responsáveis por outros processos no meio terrestre (p. ex., polinizam plantas, controlam pragas, servem como alimento a insetívoros terrestres), demonstrando a ligação entre os componentes terrestres e aquáticos dos ecossistemas.

\section{Resultados e Discussão}

Três pontos da proposta substitutiva ao Projeto de Lei $\mathrm{n}^{\circ}$ 1.876/1999 serão discutidos com maior detalhe por estarem mais diretamente relacionados com a manutenção da integridade da ictiofauna.

\section{1. Áreas de preservação permanente às margens de rios}

As áreas de preservação permanente são coincidentes com parte das zonas ripárias, que podem ser definidas como áreas de transição semiterrestres regularmente influenciadas pela água doce, normalmente se estendendo desde as margens dos corpos d'água até as bordas das comunidades das terras mais altas (Naiman et al. 2005). Pela própria definição, entende-se que os limites das zonas ripárias não são facilmente identificados e podem variar em função da sazonalidade (Lima \& Zakia 2000). Alguns estudos sugerem que $18 \mathrm{~m}$ (Barton et al. 1985), 30 (Clinnick 1985) ou 50 m em cada margem (Kasyak 2001) seriam adequados para garantir a proteção de organismos e processos ecológicos nessa área. A legislação Brasileira vigente, de acordo com a Lei nº 7.803 de 18/07/1989, dispõe que a largura da Área de Preservação Permanente (APP) varia de acordo com a largura do curso d'água, sendo de $30 \mathrm{~m}$ para cursos d'água com menos de $10 \mathrm{~m}$ de largura, situação em que se encaixa a grande maioria dos riachos brasileiros.

Dentre as modificações propostas ao Código atual, está a diminuição das faixas marginais em cursos d'água de pequeno porte (até $5 \mathrm{~m}$ de largura) que passaria a ter $15 \mathrm{~m}$ em cada margem (atualmente são $30 \mathrm{~m}$ ). Se atualmente já é notável o déficit de proteção nas áreas de proteção permanente (vide Silva et al. 2007a), com a aprovação da nova lei, esse déficit certamente será ampliado. Isso afetaria a grande maioria dos cursos d'água brasileiros e traria grandes prejuízos em termos de perdas de diversidade local e regional, pelos motivos já levantados e por expor mais ainda à degradação ecossistemas submetidos a outras ameaças (p. ex., invasão de espécies exóticas, poluição, construção de estradas). Somente na última lista de espécies ameaçadas do Estado de São Paulo (Oyakawa et al. 2009), das 66 espécies de peixes classificadas em algum grau de ameaça, 45 mostram alta fidelidade a riachos e, portanto, são dependentes da qualidade do hábitat circundante e interno. Em um estudo mais recente, Nogueira et al. (2010) detectaram que 819 espécies de peixes com área de vida restrita poderiam ser enquadradas em categorias de ameaça conforme a IUCN (2001), indicando que mais de um terço da diversidade de peixes de água doce corre sérios de extinção riscos a curto e médio prazo.

Considerando drenagens em regiões com relevo suave, é possível identificar um gradiente de perda de qualidade do hábitat associado ao processo de degradação da floresta adjacente aos riachos, quase sempre resultado do incremento da entrada de sedimentos e maior insolação no curso d'água. Na presença de floresta ripária com alta qualidade, a ictiofauna apresenta alta riqueza de espécies, nenhuma contribuição de espécies exóticas, baixa dominância e alta contribuição de itens alóctones (sementes, frutos e insetos terrestres) na sua dieta (Lorion \& Kennedy 2009, Ferreira 2010). Em situações de extremo assoreamento, o leito do canal encontra-se coberto por sedimentos finos, o volume de hábitat e o fluxo de água estão notadamente reduzidos, caracterizando condições muito favoráveis ao estabelecimento de macrófitas aquáticas enraizadas emersas, especialmente do gênero Typha e, neste cenário, a ictiofauna é dominada por espécies acidentais, oportunistas e com habilidade para consumir detritos orgânicos, que se torna o item alimentar dominantes nessas circunstâncias (Rocha et al. 2009), acarretando diminuição de biomassa íctica, perdas de espécies mais sensíveis e maiores chances de homogeneização biótica (Casatti et al. 2009, Ferreira 2010, Teresa \& Casatti 2010).

Na nova proposta em foco está contemplada a alteração do referencial para demarcação da faixa de preservação permanente às margens de rios, que deixa de ser o leito maior, conforme disposto na legislação vigente, e passa a ser o leito menor. Essas demarcações sofrem influência das variações sazonais associadas à dinâmica dos cursos d'água que promovem trocas entre o meio aquático e o ripário (Wantzen et al. 2008). As árvores da floresta ripária são adaptadas a solos permanentemente saturados e essas zonas alagadas laterais ("wetland pools") são biorreatores de processamento de matéria orgânica e estocagem temporária; durante as águas baixas, essas áreas recebem material alóctone (p.ex., folhas, sementes, insetos) e trocam esse material com o curso d'água durante as cheias (Wantzen et al. 2008). Qualquer diminuição na proteção da dimensão lateral dos cursos d'água pode alterar as entradas de material orgânico e inorgânico, com consequências para todo o sistema aquático.

$\mathrm{O}$ conhecimento produzido frente à diversidade de organismos do ecótone terra/água de diferentes biomas brasileiros ainda é incipiente para permitir generalizações sobre o tamanho mínimo ideal de proteção ripária. Por exemplo, as veredas do Cerrado brasileiro são formações que se estendem de 30 a $150 \mathrm{~m}$ a partir da margem dos riachos e abrigam alta diversidade de plantas e animais, sendo um sistema extremamente vulnerável à erosão (Wantzen et al. 2006). $\mathrm{Na}$ Amazônia, em regiões de águas claras ou pretas, os igarapés de terra firme demonstram-se muito distintos dos igapós (Walker 1990), indicando diferentes níveis de dependência entre os sistemas aquáticos e as florestas adjacentes. Essas constatações sugerem que as funções desempenhadas pela floresta ripária com relação à biota aquática são muito diversas e podem variar ao logo dos gradientes ambientais que definem os diferentes biomas brasileiros, e também indica um assunto prioritário para a pesquisa científica. $\mathrm{Na}$ falta de conhecimento científico, é fundamental prezar pela ação mais cautelosa possível. 


\section{Reservas legais}

Há previsão de que, diante da nova proposta, as áreas terrestres protegidas pela Reserva Legal diminuam. Nos estudos realizados por Harding et al. (1998), Teels et al. (2006), Lévêque et al. (2008) e autores lá listados, fica claro que, para proteger a biodiversidade aquática e garantir os processos ecológicos nestes ambientes, é necessário proteger a maior parte das bacias hidrográficas, uma vez que somente a restauração de faixas ripárias adjacentes a riachos é insuficiente para melhorar a integridade do sistema como um todo. Essas constatações são especialmente críticas quando considerado o grau de susceptibilidade do solo de muitas bacias intensamente usadas para produção de alimentos (vide p. ex., Silva et al. 2007b), gerando um cenário de incremento de assoreamento e perda de importantes micro-hábitats aquáticos. Por exemplo, Wantzen (2006) registrou no Cerrado brasileiro que uma única voçoroca pode carrear 60 toneladas de sedimentos/dia para o interior de um riacho. Assim, a diminuição das áreas florestais naturais nas Reservas Legais, previsível diante das modificações propostas ao Código Florestal em vigência, terá um papel negativo à manutenção das comunidades aquáticas.

\section{Regiões com altitudes superiores a $1.800 \mathrm{~m}$}

A estabilidade de substrato, regime hidrológico, parâmetros populacionais e de história de vida em riachos de alta altitude tem sido pouco estudados na região tropical como um todo (Jacobsen 2008). As baixas temperaturas e limitação de oxigênio podem gerar menores taxas de crescimento e de produção secundária do que em riachos de menores altitudes (Jacobsen 2008) e essa pressão seletiva se reflete na composição da fauna aquática, que apresenta alto endemismo e distribuição restrita. Com a nova proposta, não haverá necessidade de proteção de áreas com altitudes superiores a $1.800 \mathrm{~m}$ o que, para a fauna aquática, significará perdas de espécies únicas e de processos pouco conhecidos. Como regiões de altitude também abrigam nascentes de importantes corpos aquáticos, a qualidade desses recursos à jusante também será negativamente afetada.

\section{Conclusões}

Rios, riachos e a paisagem adjacente compreendem sistemas extremamente diversos, dos quais ainda precisamos conhecer muito sobre padrões e processos ecológicos. Por outro lado, o que já conhecemos a respeito desses ecossistemas indica que qualquer alteração que se traduza em diminuição da vegetação nativa atual, seja em áreas de preservação permanente, em reservas legais ou em áreas de altitude elevada, pode gerar perdas de espécies, homogeneização faunística e diminuição de biomassa íctica, com prejuízos não só à biota aquática, mas também às populações humanas que dependem destes recursos.

\section{Referências Bibliográficas}

ANGERMEIER, P.L. \& KARR, J.R. 1984. Fish communities along environmental gradients in a system of tropical streams. In Evolutionary ecology of neotropical freshwater fishes (T.M. Zaret, ed.). The Hague, Netherlands, p.39-57.

BARRELA, W., PETRERE Jr., M., SMITH, W.S. \& MONTAG, L.F. 2001. As relações entre as matas ciliares, os rios e os peixes. In Matas ciliares: conservação e recuperação (R.R. Rodrigues \& H.F. Leitão Filho, ed.). EDUSP, FAPESP, São Paulo, p.187-207.

BARTON, D.R., TAYLOR, W.D. \& BIETTE, R.M. 1985. Dimensions of riparian buffer strips required to maintain trout habitats in southern Ontario streams. N. Am. J. Fish. Manag. 5:364-378.

BERKMAN, H.E. \& RABENI, C.F. 1987. Effect of siltation on stream fish communities. Env. Biol. Fish. 18:285-294.
BUCKUP, P.A. 1999. Sistemática e biogeografia de peixes de riachos. In Ecologia de peixes de riachos (E.P. Caramaschi, R. Mazzoni \& P.R. Peres-Neto, ed.). PPGE-UFRJ, Rio de Janeiro, p.91-138. Série Oecologia Brasiliensis, 6.

BUCKUP, P.A., MENEZES, N.A. \& GHAZZI, M.S. 2007. Catálogo das espécies de peixes de água doce do Brasil. Museu Nacional, Rio de Janeiro.

CASATTI, L., FERREIRA, C.P. \& CARVALHO, F.R. 2009. Grass-dominated stream sites exhibit low fish species diversity and dominance by guppies: an assessment of two tropical pasture river basins. Hydrobiologia 632:273-283

CHAPMAN, L.J. \& CHAPMAN, C.A. 2002. Tropical forest degradation and aquatic ecosystems: our current state of knowledge. In Conservation of freshwater fishes: options for the future (M.J. Collares-Pereira, I.G. Cowx \& M.M. Coelho, ed.). Blackwell Science, Oxford, p.237-249.

CLINNICK, P.F. 1985. Buffer strip management in forest operations: a review. Aust. For. 48(1):34-45

CROOK, D.A. \& ROBERTSON, A.I. 1999. Relationships between riverine fish and woody debris: implications for lowland rivers. Mar. Fresh. Res. 50:942-953.

FERREIRA, C.P. 2010. Estrutura da ictiofauna e integridade biótica de riachos em fragmentos florestais remanescentes no noroeste paulista. Tese de Doutorado, Universidade Estadual Paulista, São José do Rio Preto.

GREGORY, S.V., SWANSON, F.J., McKEE, W.A. \& CUMMINS, K.W. 1991. An ecosystem perspective of riparian zones. BioScience 41:540-551.

HARDING, J.S., BENFIELD, E.F., BOLSTAD, P.V., HELFMAN, G.S. \& JONES III, E.B.D. 1998. Stream biodiversity: the ghost of land use past. Proc. Nat. Ac. Sc. 95:14843-14847.

IUCN. 2001. IUCN red list categories and criteria: version 3.1. Gland, Switzerland and Cambridge.

JACOBSEN, D. 2008. Tropical high-altitude streams. In Tropical stream ecology (D. Dudgeon, ed.). Elsevier, London, p.219-253.

KASYAK, P.F. 2001. Maryland biological stream survey: sampling manual. Maryland Department of Natural Resources, Monitoring and Non-tidal Assessment Division, Annapolis.

LESTER, R.E., WRIGHT, W. \& JONES-LENNON, M. 2007. Does adding wood to agricultural streams enhance biodiversity? An experimental approach. Mar. Fresh. Res. 58:687-698.

LÉVÊQUE, C., OBERDORFF, T., PAUGY, D., STIASSNY, M.L.J. \& TEDESCO, P.A. 2008. Global diversity of fish (Pisces) in freshwater Hydrobiologia 595:545-567.

LEWINSOHN, T.M. \& PRADO, P.I. 2005. Quantas espécies há no Brasil? Megadiversidade 1(1):36-42.

LIMA, W.P. \& ZAKIA, M.J.B. 2000. Hidrologia de matas ciliares. In Matas Ciliares: conservação e recuperação (R.R. Rodrigues \& H.F. Leitão Filho, ed.). EDUSP, FAPESP, São Paulo, p.33-44.

LINTON, T.K., REID, S.D. \& WOOD, C.M. 1997. The metabolic costs and physiological consequences to juvenile rainbow trout of a simulated summer warming in the presence and absence of sublethal ammonia Trans. Am. Fish. Soc. 126:259-272.

LLEWELLYN, L.C. 1973. Spawning, development, and temperature tolerance of the spangled perch, Madigania unicolor (Gunther), from inland waters of Australia. Austr. J. Mar. Fresh. Res. 24:73-94.

LORION, C.M. \& KENNEDY, B.P. 2009. Riparian forest buffers mitigate the effects of deforestation on fish assemblage in tropical headwater streams. Ecol. Appl. 19(2):468-479.

LOWE-McCONNELL, R.H. 1999. Estudos ecológicos de comunidades de comunidades de peixes tropicais. EDUSP, São Paulo.

MARCZAK, L.B. \& RICHARDSON, J.S. 2007. Spiders and subsidies: results from the riparian zone of a coastal temperate rainforest. J. An. Ecol. 76(4):687-94.

MORGAN II, R.P., RASIN Jr., J. \& NOE, L.A. 1983. Sediment effects on eggs and larvae of striped bass and white perch. Trans. Am. Fish. Soc. 112:220-224

NAIMAN, R.J. \& DÉCAMPS, H. 1997. The ecology of interfaces: riparian zones. Ann. Rev. Ecol. Syst. 28:621-658. 
NAIMAN, R.J., DÉCAMPS, H. \& McCLAIN, M.E. 2005. Riparia: ecology, conservation, and management of streamside communities. Elsevier Academic Press, Burlington.

NEUMANN, R.M. \& WILDMAN, T.L. 2002. Relationships between trout habitat use and woody debris in two southern New England streams. Ecol. Fresh. Fish 11:240-250.

NOGUEIRA, C., BUCKUP, P.A., MENEZES, N.A., OYAKAWA, O.T., KASECKER, T.P., RAMOS NETO, M.B. \& SILVA, J.M.C. 2010. Restricted-range fishes and the conservation of Brazilian freshwaters. PLOS One 5(6): 1-10

OYAKAWA, O.T., MENEZES, N.A., SHIBATTA, O.A., LIMA, F.C.T., LANGEANI, F., PAVANELLI, C., NIELSEN, D.T.B. \& HILSDORF, A.W.S. 2009. Peixes de água doce. In Fauna Ameaçada de Extinção no Estado de São Paulo (P.M. Bressan, M.C.M. Kierulff \& A.M. Sugieda, coord.). Governo do Estado de São Paulo, Secretaria de Meio Ambiente, Fundação Parque Zoológico de São Paulo, p.349-424.

PUSEY, B.J. \& ARTHINGTON, A.H. 2003. Importance of the riparian zone to the conservation and management of freshwater fish: a review. Mar. Fresh. Res. 54:1-16.

PUSEY, B.J. \& ARTHINGTON, A.H., CLOSE, P.G. \& BIRD, J. 2001. Larval fishes in rainforest streams: patterns of abundance and microhabitat use. J. Roy. Soc. Queensland 110:27-96.

RABENI, C.F. \& SMALE, M.A. 1995. Effects on siltation on stream fishes and the potential mitigating role of the buffering riparian zone. Hydrobiologia 303:211-219.

ROCHA, F.C., CASATTi, L., CARVAlHo, F.R. \& SilVA, A.M. 2009. Fish assemblages in stream stretches occupied by cattail (Typhaceae, Angiospermae) stands in Southeast Brazil. Neotr. Ichthyol. 7(2):241-250

SCHNEIDER, K.N. \& WINEMILLER, K.O. 2008. Structural complexity of woody debris patches influences fish and macroinvertebrate species richness in a temperate floodplain river system. Hydrobiologia 610:235-244.
SILVA, A.M., NALON, M.A., KRONKA, F.J.A.N., ÁlVARES, C.A., CAMARGO, P.B. \& MARTINELLI, L.A. 2007a. Historical land-cover/ use in different slope and riparian buffer zones in watershed of the State of São Paulo, Brazil. Sci. Agric. 64(4):325-335.

SILVA, A.M., CASATTI, L., ÁLVARES, C.A., LEITE, A.M., MARTINELLI, L.A. \& DURRANT, S.F. 2007b. Soil loss risk and habitat quality in streams of a meso-scale river basin. Sci. Agric. 64(4):336-343.

TEELS, B.M., REWA, A.A. \& MYERS, J. 2006. Aquatic condition response to riparian buffer establishment. Wild. Soc. Bul. 34:927-935.

TERESA, F.B. \& CASATTI, L. 2010. Importância da vegetação ripária degradada em região intensamente desmatada no sudeste do Brasil: um estudo com peixes de riacho. Panamjas, in press.

TOWNSEND, S.A. \& DOUGLAS, M.M. 2000. The effect of three fire regimens on stream water quality, water yield and export coefficients in a tropical savanna (Northern Australia). J. Hydrol. 229:118-137.

TUNDISI, J.G. \& TUNDISI, T.M. 2008. Limnologia. Oficina de Textos, São Paulo.

WALKER, I. 1990. Amazonian streams ans small rivers. In Limnology in Brazil (T.M. Tundisi, J.G. Tundisi \& C.E.M. Bicudo, ed.). Academia Brasileira de Ciências e Sociedade Brasileira de Limnologia, Rio de Janeiro, p.167-193.

WANTZEN, K.M. 2006. Physical pollution: effects of gully erosion in a tropical clear-water stream. Aq. Cons. 16:733-749.

WANTZEN, K.M., SÁ, M.F.P., SIQUEIRA, A. \& NUNES DA CUNHA, C. 2006. Conservation scheme for forest-stream ecosystems of the Brazilian Cerrado and similar biomes in the seasonal tropics. Aq. Cons. 16:713-732.

WANTZEN, K.M., YULE, C.M., TOCKNER, K. \& JUNK, W.J. 2008. Riparian wetlands of tropical streams. In Tropical stream ecology (D. Dudgeon, ed.). Elsevier, London, p.199-217.

Recebido em 31/08/2010

Versão reformulada recebida em 13/10/2010

Publicado em 15/10/2010 